\title{
Suppression of Cathepsins B and L Causes a Proliferation of Lysosomes and the Formation of Meganeurites in Hippocampus
}

\author{
Eric Bednarski, ${ }^{1}$ Charles E. Ribak, ${ }^{2}$ and Gary Lynch ${ }^{1}$ \\ ${ }^{1}$ Center for the Neurobiology of Learning and Memory, and 2Department of Anatomy and Neurobiology, University of \\ California, Irvine, California 92697
}

\begin{abstract}
Cultured hippocampal slices exhibited prominent ultrastructural features of brain aging after exposure to an inhibitor of cathepsins B and $\mathrm{L}$. Six days of treatment with $\mathrm{N}$-CBZ-Lphenylalanyl-L-alanine-diazomethylketone (ZPAD) resulted in a dramatic increase in the number of lysosomes in the perikarya of neurons and glial cells throughout the slices. Furthermore, lysosomes in CA1 and CA3 pyramidal cells were not restricted to the soma but instead were located throughout dendritic processes. Clusters of lysosomes were commonly found within bulging segments of proximal dendrites that were notable for an absence of microtubules and neurofilaments. Although pyknotic nuclei were sometimes encountered, most of the cells in slices exposed to ZPAD for $6 \mathrm{~d}$ appeared relatively normal. Slices given $7 \mathrm{~d}$ of recovery contained several unique features, compared with those processed immediately after incubation with the inhibitor. Cell bodies of CA1 neurons were largely cleared of the excess lysosomes but had gained fusiform, somatic extensions that were filled with fused lysosomes and related complex, dense bodies. These appendages, similar in
\end{abstract}

form and content to structures previously referred to as "meganeurites," were not observed in CA3 neurons or granule cells. Because meganeurites were often interposed between cell body and axon, they have the potential to interfere with processes requiring axonal transport. It is suggested that inactivation of cathepsins $B$ and $L$ results in a proliferation of lysosomes and that meganeurite generation provides a means of storing residual catabolic organelles. The accumulated material could be eliminated by pinching off the meganeurite but, at least in some cases, this action would result in axotomy. Reduced cathepsin L activity, increased numbers of lysosomes, and the formation of meganeurites are all reported to occur during brain aging; thus, it is possible that the infusion of ZPAD into cultured slices sets in motion a greatly accelerated gerontological sequence.

Key words: lysosomal hydrolase; meganeurite; ageing; Alzheimer's disease; hyperplasia; dysfunction; neurodegeneration; aged; cortex
Infusion of chloroquine or leupeptin into the lateral ventricles of young rats causes the appearance of morphological features that are normally seen only in the aged brain. These include an accumulation of lipofuscin (Ivy et al., 1984, 1989a; Nunomura and Miyagishi, 1993), a build-up of abnormally phosphorylated tau proteins in neuronal perikarya and dendrites (Ivy et al., 1989b; Takauchi and Miyoshi, 1995), increased levels of potentially amyloidogenic fragments (Hajimohammadreza et al., 1994), a decline in dopamine $\mathrm{D}_{2}$ receptors in striatum (Shibata et al., 1992), and distended initial segments of axons (Cavanagh et al., 1993). Chloroquine is an acidotropic agent that disrupts protein degradation in lysosomes (Ohkuma, 1987), whereas the predominant action of leupeptin is to block cysteine proteases (Toyo-Oka et al., 1978; Neff et al., 1979). Accordingly, lysosomal cysteine proteases are the likely common targets of the drugs and, from the results cited above, it would appear that a subgroup of these enzymes is closely linked to well-established correlates of brain aging. These conclusions raise the possibility that naturally occurring reductions in the activities of particular lysosomal cysteine proteases are responsi-

Received Oct. 2, 1996; revised March 7, 1997; accepted March 12, 1997.

This work was supported by National Institute of Aging Grant AG00538 and National Institute of Mental Health, National Research Service Award MH14599. We wish to thank Marian Shiba-Noz, John Han, Sue Fisher, and Zsolt Toth for technical help.

Correspondence should be addressed to Dr. Eric Bednarski, Center for the Neurobiology of Learning and Memory, University of California, Irvine, CA 926973800 .

Copyright (C) 1997 Society for Neuroscience $0270-6474 / 97 / 174006-16 \$ 05.00 / 0$ ble for some of the alterations that emerge in brain in later life. Of interest with regard to this idea is the report that the activity of cathepsin L, one of the most efficient of lysosomal cysteine endopeptidases (Kirschke and Barrett, 1985; Bohley and Seglen, 1992), decreases by $90 \%$ from 2 to 28 months in the neocortex, hippocampus, striatum, and cerebellum of the rat (Nakanishi et al., 1994). Age-related losses do not occur for all cysteine lysosomal hydrolases; the activity of cathepsin B is reported to remain relatively constant in brain throughout the life span of the rat except in the striatum, where it increases in old age (Nakanishi et al., 1994). In all, then, the effects induced by leupeptin/chloroquine may be aspects of a brain-aging progression normally initiated by declines in the activity of a select group of lysosomal proteases.

Additional experimental work on the above ideas would be facilitated by compounds that have a greater degree of selectivity for the pertinent enzymes and by test systems that allow for precise applications of drugs as well as for reliable collection of physiological/biochemical measures of drug effects. Recent efforts in these directions have made use of (1) the compound $N$-CBZ-L-phenylalanyl-L-alanine-diazomethylketone (ZPAD), a selective inhibitor of cathepsins B and L (Green and Shaw, 1981; Pliura et al., 1992), and (2) newly introduced techniques for preparing and maintaining cultured hippocampal slices. Regarding the latter, Muller et al. (1993) found that slices prepared from rats in the second postnatal week and supported in an interface chamber develop and stably maintain a number of adult charac- 
teristics not typically found in organotypic cultures. A system such as this could have considerable advantages for testing the effects of chronic drug administration on variables specific to the adult brain (see Bahr et al., 1995a).

Initial experiments testing the effects of ZPAD on cultured slices found that 4-6 d applications resulted in (1) an increase in the lysosomal concentration of cathepsin D, (2) an escape of active cathepsin D from lysosomes, and (3) the appearance of a cytosolic tau protein fragment (Bednarski and Lynch, 1996). The cathepsin D findings are of particular interest, because the activity of this enzyme increases with age in homogenates and extralysosomal cellular fractions of rat brain (Nakamura et al., 1989; Nakanishi et al., 1994). Moreover, enzymatically active cathepsin D occurs in proximity to senile plaques (Cataldo and Nixon, 1990) and may, because of its substrates, contribute to other more advanced signs of aging (microtubule disruption) (see Bednarski and Lynch, 1996).

The present studies tested whether suppression of cathepsins B and L results in the appearance of greatly expanded initial segments of axons ("meganeurites," Purpura and Suzuki, 1976; or "fusiform bodies," Braak, 1979) in hippocampal slices. A related goal of this work was to determine whether inhibition of the proteases causes an increase in the number of lysosomes, an effect that would account for ZPAD-induced increases in cathepsin D, and whether this has any relationship to meganeurite formation. Previous workers have hypothesized that expansion of axon initial segments during aging or as part of a disease process is attributable to lysosomal dysfunction (Purpura et al., 1978; Braak and Goebel, 1979), but it has not been possible to search for connections between changes in lysosomes and the emergence of anatomical abnormalities.

\section{MATERIALS AND METHODS}

Cultured hippocampal slices. Hippocampal slices were prepared from 11to 12-d-old Sprague Dawley rats and maintained in culture using methods described by Stoppini et al. (1991). The upper surfaces of the slices were exposed to a humidified, $37^{\circ} \mathrm{C}$ atmosphere containing $5 \% \mathrm{CO}_{2}$. The culture medium was composed of $50 \%$ basal medium eagle, $25 \%$ Earle's balanced salt solution, 25\% donor horse serum (Gemini Bio-Products, Calabasas, CA), and the following supplements (in $\mathrm{mm}$ ): $136 \mathrm{NaCl}, 2$ $\mathrm{CaCl}_{2}, 2.5 \mathrm{MgSO}_{4}, 5 \mathrm{NaHCO}_{3}, 3$ glutamine, 40 glucose, 0.5 ascorbic acid, 20 HEPES buffer, $\mathrm{pH} 7.3$, at $23^{\circ} \mathrm{C}$, and $1 \mathrm{mg} / 1$ insulin, $5 \mathrm{U} / \mathrm{ml}$ penicillin, and $5 \mathrm{mg} / \mathrm{l}$ streptomycin. Each of the above components, with the exception of the horse serum, was obtained from Sigma (St. Louis, MO). During the initial $10 \mathrm{~d}$ in culture, slices develop a variety of adult characteristics, including myelination, well-developed dendritic spines, a high synaptic density, and the capacity for long-term potentiation (Buchs et al., 1993; Muller et al., 1993; Bahr et al., 1995b; Vanderklish et al., 1996). Slices were maintained in vitro at least $9 \mathrm{~d}$ before experiments were started.

Experiments were initiated by exposing a subset of organotypic slices from a culture plate to $40-45 \mu \mathrm{M}$ ZPAD (BACHEM Bioscience, Torrance, $\mathrm{CA}$ ), an inhibitor of cathepsins $\mathrm{B}$ and $\mathrm{L}$. A culture plate contained hippocampal explants from one animal only. The base medium applied to slices (both control and treated) during the experiments was identical to the culture medium described above, except that the horse serum was heat-treated $\left(35 \mathrm{~min}\right.$ at $\left.56^{\circ} \mathrm{C}\right)$. Media exposed to control hippocampal slices additionally contained a suitable amount of drug diluent (DMSO). The media were replenished every $48-72 \mathrm{hr}$.

After 2-3 d of treatment, a subset of control and ZPAD-exposed slices were subjected to three different enzymatic assays to determine the specificity and effectiveness of the inhibitor. Other hippocampal slices were exposed to equivalent doses of the inhibitor for $6 \mathrm{~d}(n=5)$ before being immediately processed for electron microscopy with their matched control $(n=4)$ cultures. In addition, a subset of control $(n=3)$ and ZPAD-treated $(n=4)$ slices was maintained in culture (supplemented with regular culture medium) for an additional $7 \mathrm{~d}$ before fixation and processing for electron microscopy.
Assay for the determination of cathepsin B and L activities. Cathepsin activities were determined using a modified version of a method described previously (Barrett and Kirschke, 1981). Briefly, control and ZPAD-treated hippocampal slices were collected in ice-cold buffer containing $20 \mathrm{~mm}$ Tris, $0.30 \mathrm{M}$ sucrose, and $1 \mathrm{~mm}$ EDTA, pH 7.4, and centrifuged at $12,000 \times g$ for $5 \mathrm{~min}$ at $4^{\circ} \mathrm{C}$. The supernatants were aspirated, and the pellets were resuspended in lysis buffer $(55.2 \mathrm{mM}$ $\mathrm{KH}_{2} \mathrm{PO}_{4}, 11.5 \mathrm{~mm} \mathrm{NaHPO}, 4$ mm EDTA, $\mathrm{pH} 4.7$ ). After tip sonication and Bradford (1976) analyses, samples containing $40 \mu \mathrm{g}$ of protein were maintained at $20^{\circ} \mathrm{C}$ for $18-24 \mathrm{hr}$, diluted into assay buffer $(340 \mathrm{~mm}$ sodium acetate, $60 \mathrm{~mm}$ acetic acid, $4 \mathrm{~mm}$ EDTA, and freshly prepared 8 $\mathrm{mm}$ dithiothreitol, $\mathrm{pH} 5.4$ ), bath sonicated for $30 \mathrm{sec}$, and centrifuged at $12,000 \times \mathrm{g}$ for $12 \mathrm{~min}$ at $4^{\circ} \mathrm{C}$. The soluble fraction was removed and co-incubated with $20 \mu \mathrm{M} \mathrm{N}$-CBZ-Phe-Arg-7-amido-4-methylcoumarin (Sigma), a substrate for cathepsins $\mathrm{B}$ and $\mathrm{L}$, at $37^{\circ} \mathrm{C}$ for $10 \mathrm{~min}$. To determine the specific contributions of the two proteases, other tubes were supplemented with $0.75 \mu \mathrm{M}$ CA-074 (Peptides International, Louisville, KY), a specific inhibitor of cathepsin B (Kakegawa et al., 1993; Inubushi et al., 1994). The activity of cathepsin L, determined as the fraction insensitive to CA-074, was completely suppressed when $0.25 \mu \mathrm{M}$ chymostatin (Sigma) was added to the assay. Enzyme assays were terminated with the addition of ice-cold buffer containing $70 \mathrm{~mm}$ acetic acid, 30 $\mathrm{mm}$ sodium acetate, and $100 \mathrm{~mm}$ iodoacetic acid, $\mathrm{pH} 4.3$, and the amount of 7-amido-4-methylcoumarin liberated from substrate was quantified using a fluorescence spectrophotometer equipped with $360 \mathrm{~nm}$ excitation and $430 \mathrm{~nm}$ emission filters. Values obtained for the enzymatic activities of cathepsins B and L were transformed to nanomoles of 7-amido-4methylcoumarin (Sigma) before the calculations comparing control and experimental samples were performed.

Determination of calpain activity in control and ZPAD-exposed slices. Calpain activity assays were performed in situ by exposing control and ZPAD-infused slices to $200 \mu \mathrm{M}$ NMDA for $45 \mathrm{~min}$. Slices were then harvested into ice-cold harvest buffer ( $5 \mathrm{~mm}$ HEPES, $0.32 \mathrm{~m}$ sucrose, 1 mM EDTA, 1 mM EGTA, $0.02 \% \mathrm{NaN}_{3}, 10 \mathrm{mg} / 1$ antipain, and $2 \mathrm{mg} / 1$ each of leupeptin, aprotonin, and pepstatin, $\mathrm{pH}$ 7.4), and centrifuged at $12,000 \times g$ for $5 \mathrm{~min}$ at $4^{\circ} \mathrm{C}$. Pellets were resuspended in an estimated $10 \times$ volume of lysis buffer ( $8 \mathrm{~mm}$ HEPES, $1 \mathrm{~mm}$ EDTA, $0.3 \mathrm{~mm}$ EGTA, and the same protease inhibitors mentioned above, $\mathrm{pH} 8.0$ ) and tipsonicated. After Bradford analyses, $100 \mu \mathrm{g}$ of protein from each sample was denatured by boiling for 5 min with $2.5 \%$ (wt/vol) SDS and $3 \%$ (wt/vol) $\beta$-mercaptoethanol then subjected to SDS-PAGE on 3-17\% linear gradient gels (Laemmli, 1970). Resolved proteins were transferred to nitrocellulose, and breakdown products were labeled using antibodies to the calpain I-mediated $\mathrm{N}$-terminal fragment of $\alpha$-spectrin. This antibody has been described previously (Bahr et al., 1995c). After primary antibody incubations, immunoblots were washed and exposed to alkaline phosphatase-conjugated goat anti-rabbit IgG. Immunobands were visualized using the 5-bromo-4-chloro-3-indolyl-phosphate and nitro blue tetrazolium substrate system. Development was terminated before band intensity was saturated. A computerized image analysis system was used to quantify the mean optical density and area of each immunoband. The product of these two values was used to compare the specific immunoreactivities of the various samples.

Electron microscopy. Control and ZPAD-infused slices were fixed in an ice-cold solution of PBS, $\mathrm{pH} 7.5$, containing $4 \%$ paraformaldehyde and $1 \%$ glutaraldehyde. After $2 \mathrm{hr}$, this solution was aspirated, and the slices were washed three times in PBS. Slices were post-fixed in $2 \%$ osmium tetroxide (in $0.1 \mathrm{M}$ phosphate buffer) for $1 \mathrm{hr}$, dehydrated in a series of graded alcohols, and embedded in Polybed-812. Semithin (1 $\mu \mathrm{m})$ sections were cut from the embedded specimens and stained with $0.1 \%$ toluidine blue. These sections were used to locate the subregion of hippocampus (CA1, CA3, or dentate gyrus) to be examined ultrastructurally. After the peripheral regions of the specimen were trimmed away, thin sections were cut with a diamond knife, mounted on Formvar-coated slot grids, stained with uranyl acetate and lead citrate, and examined with a Philips (Mahwah, NJ) CM10 electron microscope.

\section{RESULTS}

\section{The morphology of cultured hippocampal slices}

The morphology of control slices maintained in culture for 15-17 d was similar to that described previously (Buchs et al., 1993). Figure $1 A$ is a photomicrograph of a toluidine blue-stained semi- 

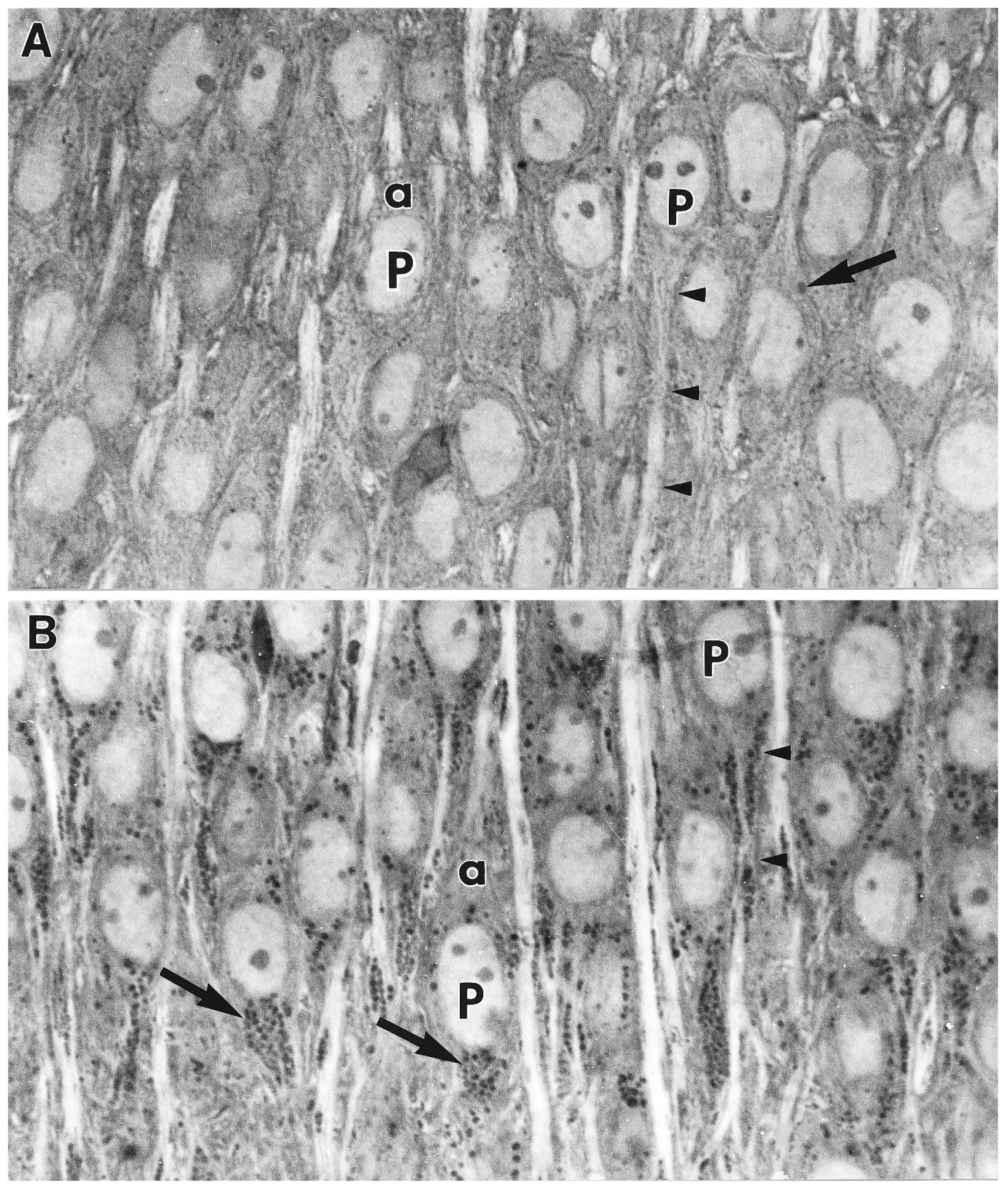

Figure 1. A, Light micrograph of a semithin section through CA1 of an untreated (control) cultured hippocampal slice maintained in vitro for $16 \mathrm{~d}$. Several pyramidal neurons $(P)$ are shown with their contiguous apical $(a)$ or basal (arrowheads) dendrites. A basophilic organelle (arrow) can be seen clearly in one CA1 neuron. Magnification, $1200 \times . B$, Light micrograph of CA1 neurons from a semithin section obtained from a cultured slice exposed to ZPAD, an inhibitor of cathepsins B and L, from culture day 11-16. The pyramidal cells $(P)$ show many of the same features as those in A, including centrally located nuclei, apical ( $a$ ) dendrites, and basal (arrowheads) dendrites. Inspection of the cytoplasm of these neurons, however, reveals a dramatic increase in the number of basophilic punctate structures (arrows). Note that many neurons show an asymmetrical distribution of the darkly stained granules in that more are found in the basal portion of their cell bodies. Magnification, $1200 \times$.

thin section through CA1 of an untreated slice. The cytoplasm of these cells is unremarkable, and the somata are characterized by the presence of large centrally located nuclei. Electron micrographs of the CA1 subfield of control hippocampal slices demonstrated the appearance of a variety of cytoplasmic organelles within pyramidal cells, including occasional electron-dense lysosomes scattered throughout the cytoplasm (Fig. $2 A$ ). The lysosomes of CA1 and CA3 neurons were $0.1-0.5 \mu \mathrm{m}$ in diameter, dimensions similar to those obtained with in vivo material (Peters et al., 1991). Apical dendrites of hippocampal neurons contained prominent, longitudinally oriented neurofilaments and microtubules together with numerous spine synapses; as is the case for hippocampus in vivo, lysosomes were rare in the dendritic ramifications (Fig. 2B). There were no evident differences between control slices collected on culture days 15-17 and those given an additional week in culture. 

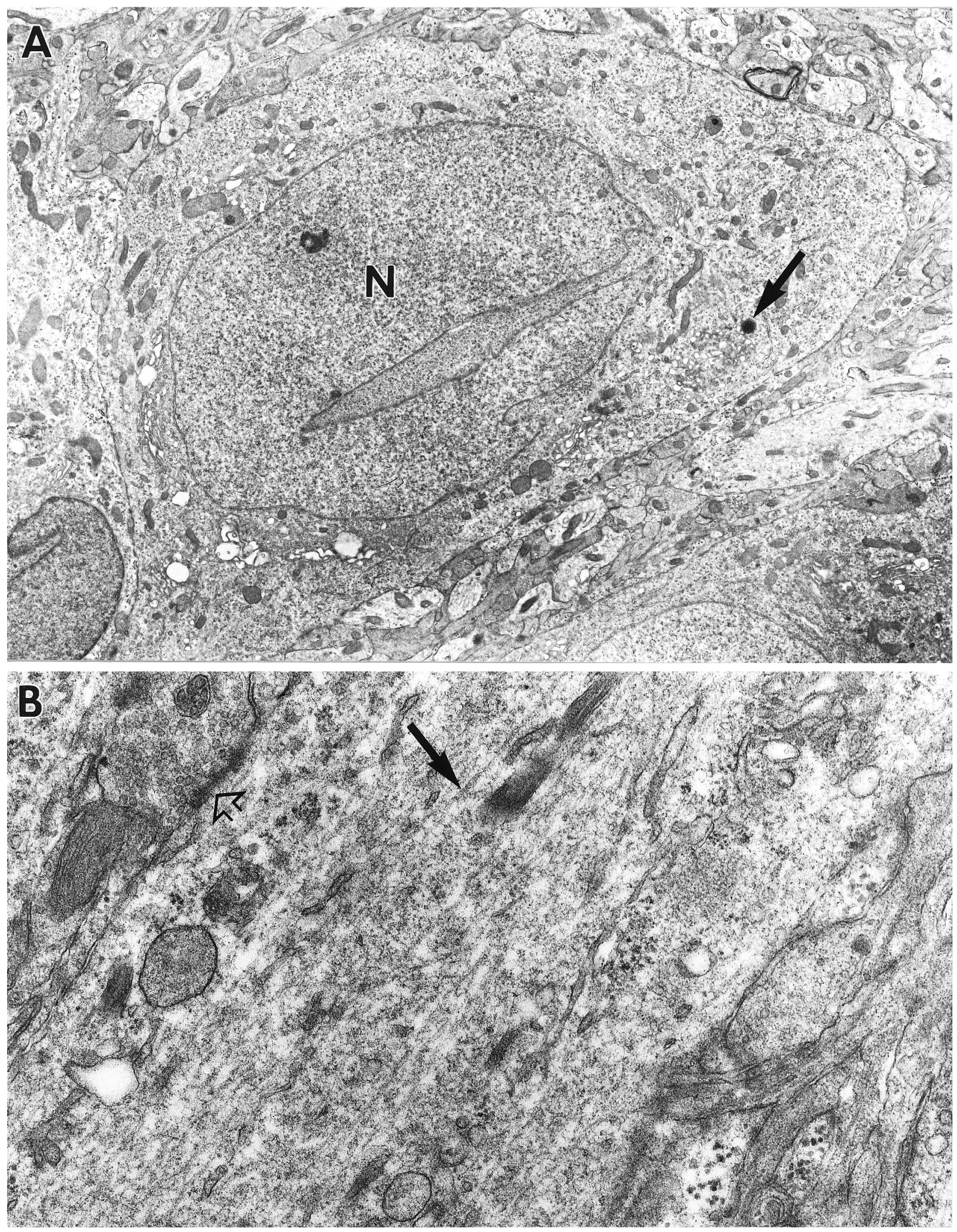

Figure 2. A, Electron micrograph of a CA1 pyramidal cell from a control cultured hippocampal slice. The nucleus $(N)$ is centrally located and surrounded by numerous cytosolic organelles, including a few lysosomes (arrow). This slice was maintained in culture for $16 \mathrm{~d}$. Magnification, $6200 \times$. B, Electron micrograph of a section of the apical dendrite from a control CA1 pyramidal cell. This portion of the process features prominent microtubules (arrow), smaller neurofilaments, and a synapse (open arrow). Magnification, 32,000×. 


\section{Effects of chronic ZPAD treatment on the activity of cathepsins $B$ and $L$}

The selectivity of the irreversible inhibitor was determined by subjecting control and ZPAD-treated slices to three different proteolytic assays. First, treatment of cultured hippocampal slices with $40 \mu \mathrm{M}$ ZPAD for $3 \mathrm{~d}$ resulted in a reduction in the activity of cathepsin B to $0.6 \pm 0.2 \%$ (mean \pm SEM) that of control levels $(p<0.001$, two-tailed $t$ test, $n=3$ ). Second, the activity of cathepsin L was suppressed by $97.8 \pm 0.1 \%$ in ZPAD-treated slices $(p<0.001$, two-tailed $t$ test, $n=3)$. Third, two previous days of ZPAD infusion did not attenuate the production of $\mathrm{N}$-terminal proteolytic fragments of spectrin by $45 \mathrm{~min}$ of NMDA receptor stimulation. Under these experimental conditions, the optical density of spectrin breakdown product immunobands was equal in NMDA-exposed slices treated with and without $\mathrm{ZPAD}$ ( $76 \pm 16$ vs $77 \pm 17, p>0.5$, two-tailed $t$ test, $n=5$ for each). Numerous studies have shown that the assayed spectrin breakdown products $(\sim 150 \mathrm{kDa})$ provide an accurate index of recent calpain activity (Lee et al., 1991; Bednarski et al., 1995). Together, then, these findings indicate that ZPAD effectively inhibited cathepsins B and L, but did not significantly suppress calpain in situ.

\section{Morphological changes induced by ZPAD}

Photomicrographs of slices exposed to ZPAD for $6 \mathrm{~d}$ revealed that a great majority of neurons throughout all subfields of hippocampus contained large numbers of basophilic densely stained granules (Fig. $1 B$ ). The granules appeared to be preferentially contained within the basal soma of several CA1 pyramidal cells. Electron microscopy confirmed that the dark granules were lysosomes. Figure $3 A$ is an electron micrograph of a CA1 neuron from a treated slice; as is evident, numerous lysosomes surround the nucleus and extend into the proximal dendrites. Note also that small dendritic processes adjacent to the cell body also contain lysosomes, a feature not seen in control material. Most of the lysosomes were larger than normal (measuring $0.73 \pm 0.07 \mu \mathrm{m}$ in diameter in CA3 neurons, $n=108$ ), with a minority being irregularly shaped and containing both vacuoles and twisted membranes (Fig. 3B). Finally, despite spreading throughout much of the dendritic cytoplasm, lysosomes were rarely observed in the axon hillock and axon initial segments of CA1 neurons from ZPAD-treated slices (Fig. 4A,B). It should be noted that lysosomal hyperplasia was not restricted to neurons; astrocytes and oligodendrocytes of ZPAD-infused slices also contained abnormally elevated numbers of lysosomes (data not shown).

Despite the dramatic increase in lysosome number, other subcellular organelles (e.g., mitochondria, Golgi complexes, and cisternae of endoplasmic reticulum) of most neurons in slices exposed to ZPAD appeared normal (Figs. $3 A, B, 4 A, 5 A$ ). Synapses were frequent and had normal constituents including vesiclecontaining terminals, spines, and postsynaptic densities (Fig. $5 A-C)$ that were not detectably different in appearance than those in control slices. However, pyknotic neurons were occasionally encountered, particularly in field CA3 (Fig. 6A).

In some large dendrites, generally those of field CA3, groups of lysosomes formed parallel aggregates that were flanked by arrays of intact microtubules and neurofilaments (Fig. 5A,B). In such cases, it appeared that a segregation had occurred between the longitudinally oriented cytoskeleton and the lysosomes. Proximal dendritic segments adjacent to large accumulations of lysosomes were often distended (Fig. 5A). Rows of lysosomes were also found $200-300 \mu \mathrm{m}$ from the cell bodies in the more distal dendritic tree (Fig. $6 \mathrm{~A}$ ); some secondary dendrites contained isolated lysosomes that were larger than the diameter of the initial portion of the branch (Fig. 6B). The above effects of ZPAD were found in all subdivisions of hippocampus, although, as noted, some were more prominent in the CA3 neurons.

\section{Effects of a $7 \mathrm{~d}$ recovery period on ZPAD-induced changes in hippocampal ultrastructure}

Slices treated with ZPAD for $6 \mathrm{~d}$ and then allowed 1 week to recover contained lysosomes significantly smaller than those described previously. Measurements taken from electron micrographs of field CA3 indicated that the lysosomes were 52\% smaller than before recovery ( $p<.001$, two-tailed $t$ test, $n=128)$. Profiles indicative of the fusion of multiple lysosomes were found throughout the pyramidal cell fields. The fused structures, which were not common in slices collected immediately after the termination of ZPAD treatment, contained electron-dense heterogeneities, whorled membranes, and vacuoles. Given their size and appearance, it can be assumed that the fused dense bodies (FDBs) were composed of secondary lysosomes, postlysosomal compartments, and autophagic vacuoles (for a description of similar profiles, see Samorajski et al., 1964; Dunn, 1990).

Except for the increase in FDBs and reduction in the size of lysosomes, field CA3 appeared little changed from the end of ZPAD infusion to the end of washout. However, alterations in addition to these were observed in the other hippocampal regions after the recovery period. These are grouped below into five categories. First, a reduction in the number of lysosomes in cell bodies and proximal dendrites of CA1 neurons was evident in recovered slices relative to slices processed immediately after ZPAD exposure (compare Figs. $7 A$ and $3 A$ ). This observation was unique to CA1 neurons. Second, lysosomes and FDBs were observed in the axon hillock and axon initial segments of CA1 neurons and granule cells. Mossy fiber terminals were commonly filled with lysosomal bodies, suggesting that granule cells routinely transported lysosomes and/or FDBs down their axons. In accord with this, solitary lysosomes were observed frequently in granule cell axons of the hilus. CA1 pyramidal cells were notable for large numbers of lysosomal bodies within the axon hillock region. Third, many CA1 neurons and granule cells exhibited somal expansions. Although some of the protuberances were located away from the basal pole of the perikarya, most were interposed between cell body and axon initial segment (Fig. 7A,B). The latter processes (meganeurites) were greatly extended, fusiform, and observed only in CA1 neurons. All of the somal expansions, regardless of size or location, contained mitochondria, ribosomes, and significant accumulations of lysosomes and FDBs. However, the interiors of longer meganeurites $(>40 \mu \mathrm{m})$ were noticeably different from those of the less developed expansions. The proximal segments of these meganeurites had organized rows of FDBs somewhat like the configuration of lysosomes frequently found in the dendrites of ZPAD-treated slices (see Fig. 6A). At increasing distances from the cell soma, unusually electron-dense and vacuolated FDBs were fused into aggregates that nearly spanned the entire width of the neuronal process (Fig. $8 A, B$ ). It is noteworthy that lysosomes and FDBs, although numerous in the fusiform expansions, were rarely seen in the contiguous axon initial segments. Fourth, groups of membrane-encircled processes filled with mitochondria, filamentous aggregates, and FDBs were frequently observed in the CA1 subfield (Fig. $8 C$ ). These apparent neurites were extremely rare in the dentate gyrus. The neurites were occasionally wrapped in myelin and had contents resembling those in the distal aspects of meganeurites (compare Fig. 8, $B$ and 

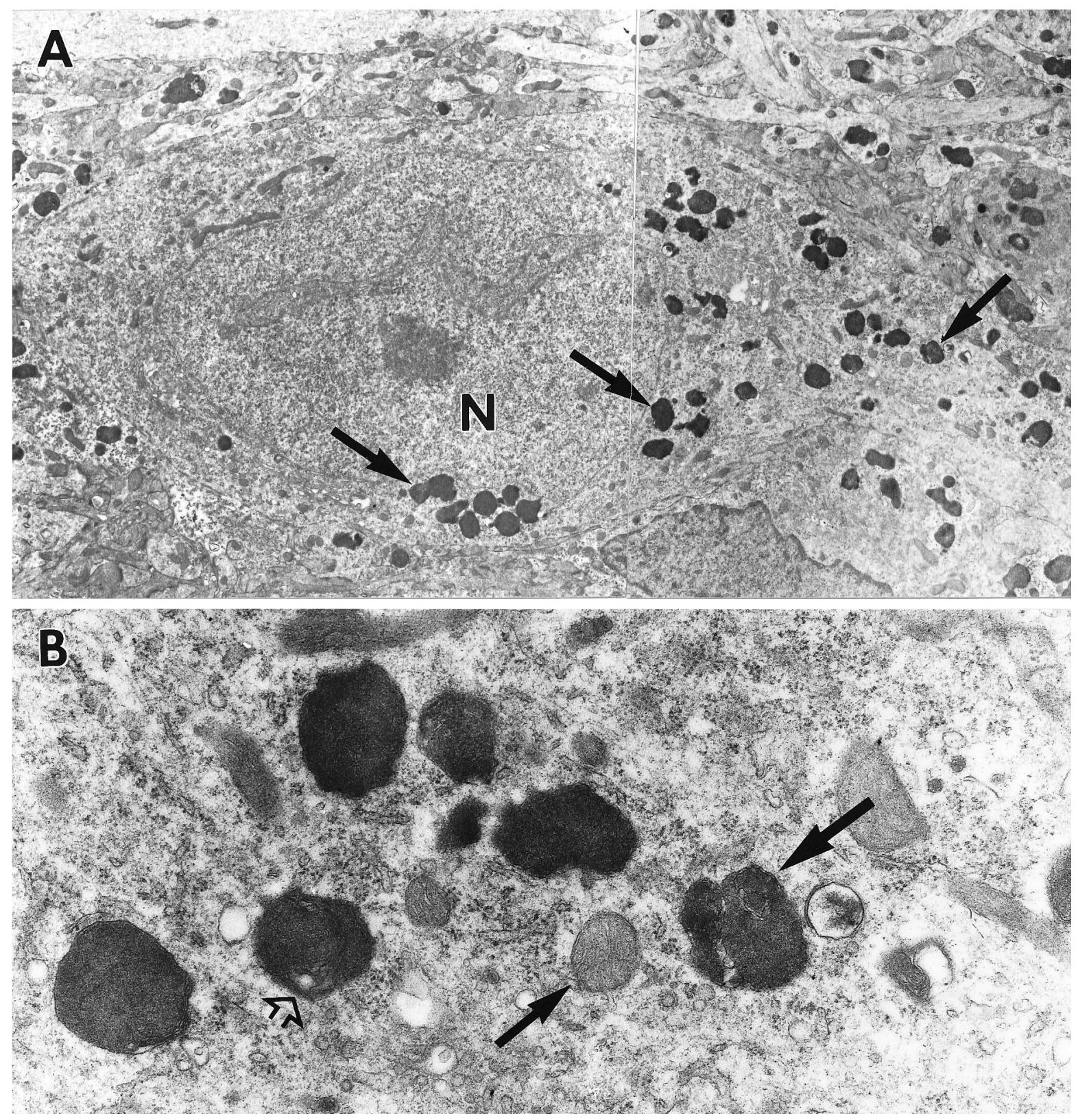

Figure 3. A, Montage of electron micrographs showing a CA1 neuron from a cultured hippocampal slice exposed to ZPAD for 6 d. Numerous lysosomes (arrows) are located in the apical portion of the perikaryon and proximal apical dendrites. The nucleus $(N)$ appears normal. Magnification, $4700 \times$. $B$, Enlargement of a portion of the soma. The milieux of some lysosomes contain twisted membranes (large arrow); other lysosomes have vacuoles of various sizes (open arrow). Mitochondria (small arrow) appear normal. Magnification, 26,500×.

$C)$. Astrocytes were commonly associated with groups of FDBfilled neurites (Figs. 9A,B). Fifth, lysosomes in CA1 neurons were frequently located in unusually close apposition to cellular membranes. Rows of lysosomes, similar to those described previously after $6 \mathrm{~d}$ of ZPAD treatment, were now present in the most lateral aspects of dendritic processes (compare Fig. 10 $A-C$ and $6 A$ ).

\section{DISCUSSION}

Incubating cultured hippocampal slices for $6 \mathrm{~d}$ with an inhibitor of cathepsins B and L caused a massive increase in the number of lysosomes. This effect provides an explanation for the earlier observation that inhibition of these enzymes results in a rapidly developing increase in the activity and concentration of the lyso- somal protease cathepsin D (Bednarski and Lynch, 1996). The cellular mechanisms responsible for lysosomal proliferation are subjects for additional studies (for discussion, see Cataldo et al., 1996). Cathepsin L, one of the cysteine proteases targeted by the drug used in the present study, is among the most efficient and potent of lysosomal endopeptidases with regard to the initial breakdown of transported proteins (Kirschke and Barrett, 1985; Kominami et al., 1991; Bohley and Seglen, 1992), and its suppression would presumably lead to the accumulation of incompletely digested proteins and proteinaceous structures (for discussion, see de Duve and Wattiaux, 1966). It is not unreasonable to assume that genes encoding lysosomal enzymes are sensitive to one or more aspects of such accumulations; if so, then upregulation of 


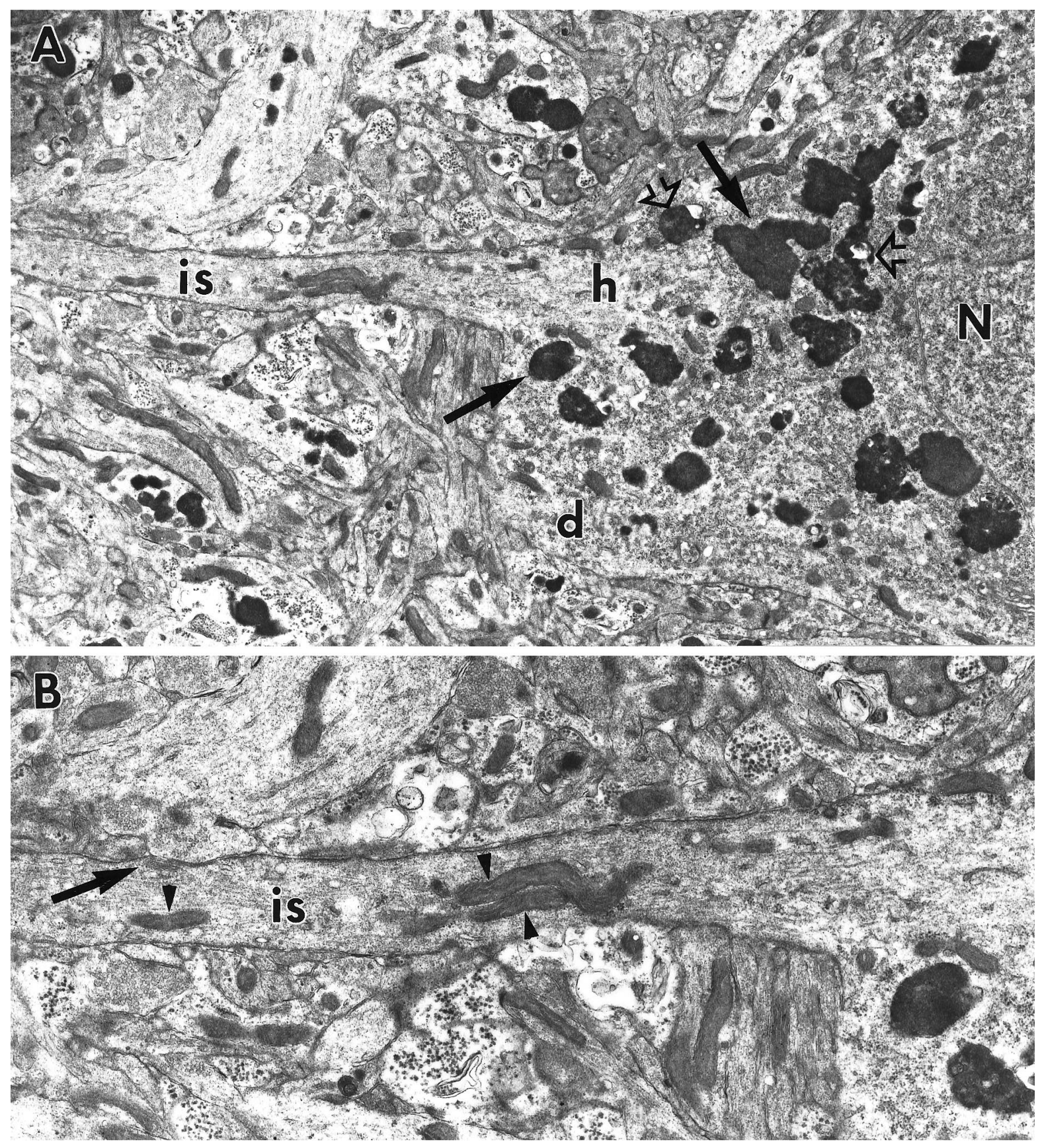

Figure 4. A, Electron micrograph of the basal portion of a CA1 pyramidal cell soma from a ZPAD-treated slice. Although numerous lysosomes (arrows) encircle the nucleus $(N)$ and are found within the proximal span of a basal dendrite $(d)$, none are observed in the axon hillock $(h)$ and initial segment (is) within this section. Vacuole-containing lysosomes (open arrows) are also evident within the perikaryal cytoplasm. Magnification, 8300×. B, Enlargement of the axon initial segment (is). Note the dense axolemmal undercoating, microtubule bundling, cisternal organelle (arrow), mitochondria (arrowheads), and paucity of lysosomes. Magnification, 15,000×.

the genes, followed by increases in the number of protease copies, could be the trigger for the expansion of the primary lysosome population. Experiments are now in progress to determine whether incubations with ZPAD produce higher concentrations of mRNAs for various lysosomal enzymes.

Suppression of cathepsins B and L for $6 \mathrm{~d}$ not only increased the number of lysosomes but also led to their translocation into the dendritic trees of the pyramidal neurons. Interestingly, the dendritic lysosomes were found near the core of primary and secondary branches and were commonly displaced from longitudinally oriented microtubular systems. The latter observation raises the possibility that the migration of lysosomes into the dendritic ramifications is not simply a reaction to the overproduction occurring in the cell bodies but also involves a disturbance of cytoskeletal structures that normally maintain the somal compartmentalization of subcellular organelles. In accord with this idea, previous work has shown that chemicals that disrupt microtubules cause a movement of lysosomes into dendrites (Herman and Albertini, 1984; Gorenstein and Ribak, 1985), an effect similar to the migration found in the present study. Also pertinent is the 


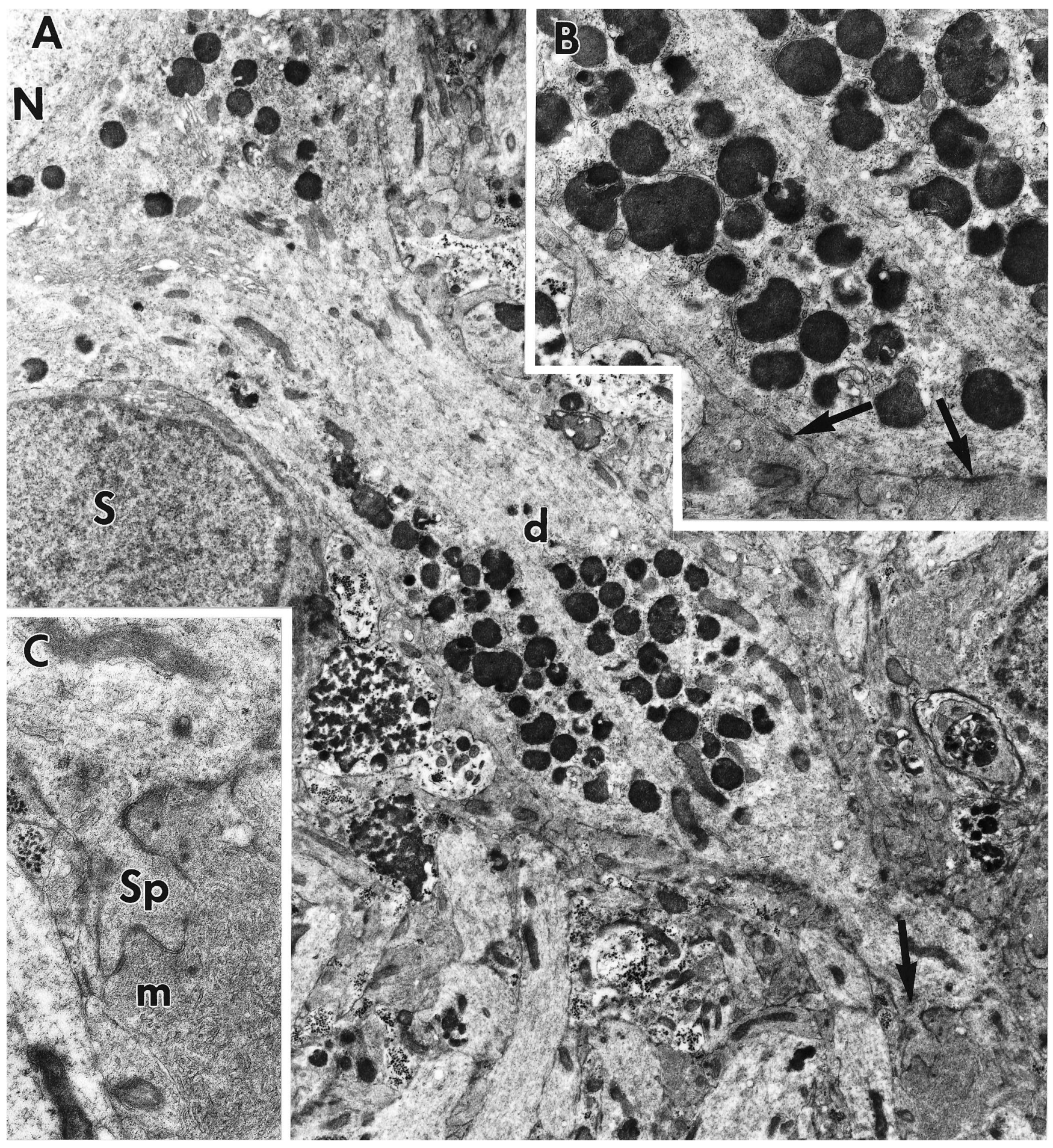

Figure 5. A, Electron micrograph of a CA3 apical dendrite from a ZPAD-treated slice. Most lysosomes are located either adjacent to the nucleus ( $N$ ) or found clustered within a bulging segment of the apical dendrite $(d)$. A spine is evident distal to the dendritic bulge $($ arrow $)$. A satellite cell $(S)$ is present alongside the dendrite. Magnification, $8000 \times . B$, Enlargement of the dendritic bulge. Intact microtubules and neurofilaments are not apparent within the two lysosomal assemblages. Note the presence of several synapses (arrows). Magnification, $15,000 \times$. $C$, Enlargement of the dendritic spine $(s p)$ noted in $A$ and accompanying mossy fiber $(m)$. Magnification, 22,000×.

finding that ZPAD-treated slices contain a cytosolic tau fragment produced by extralysosomal concentrations of cathepsin D (Bednarski and Lynch, 1996). Tau plays a pivotal role in cross-linking microtubules and in maintaining the integrity of the cytoskeleton (Weingarten et al., 1975; Goode and Feinstein, 1994), and its proteolysis by aberrantly located cathepsin $\mathrm{D}$ might well remove strictures on the movements of the lysosomes. Leakage of cathepsin D from lysosomes into the surrounding cytoplasm with subsequent cleavage of tau could also account for the microtubule free zones, in which dendritic lysosomes were found.

CA1 neurons from cultured slices exposed to ZPAD for $6 \mathrm{~d}$ and then given $7 \mathrm{~d}$ of recovery exhibited the following differences from 

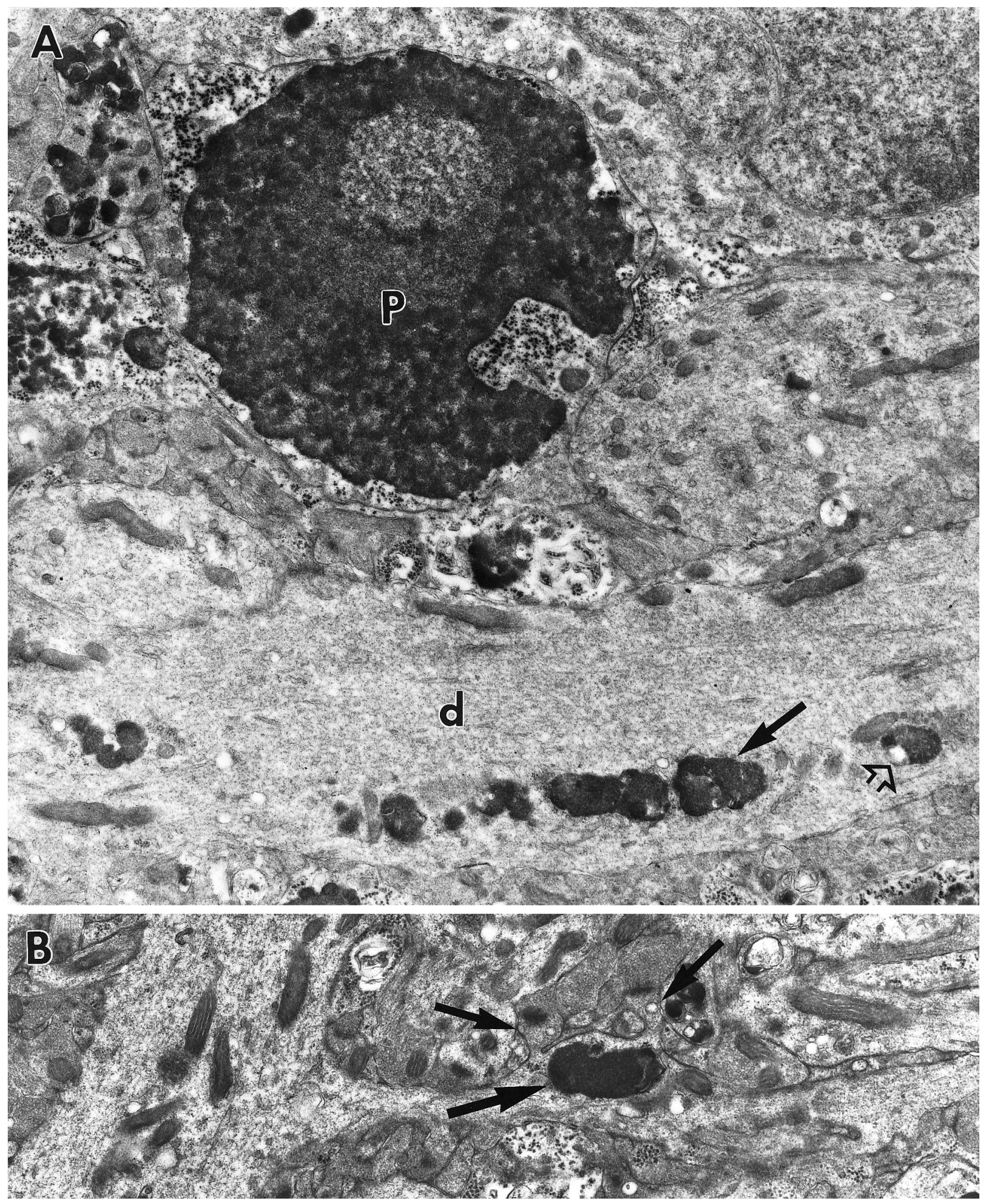

Figure 6. A, Electron micrograph of a portion of the CA3 field at the junction of the cell body layer and stratum radiatum of a slice treated with ZPAD for $6 \mathrm{~d}$. At the bottom of the field, a row of lysosomes (arrow) is found in an apical dendrite $(d)$. Note that the dendrite also contains vacuolated lysosomes (open arrow). A pyknotic nucleus $(P)$ can be seen adjacent to this dendrite. Membrane-bound cellular processes containing lysosomes and mitochondria are located around the compacted nucleus. Magnification, 13,500×. B, Micrograph of a section of CA3 stratum radiatum from a treated hippocampal slice. A large lysosome (large arrow) fills most of a swollen secondary dendrite. Flanking the lysosome are two spines (small arrows). Magnification, $15,000 \times$. 

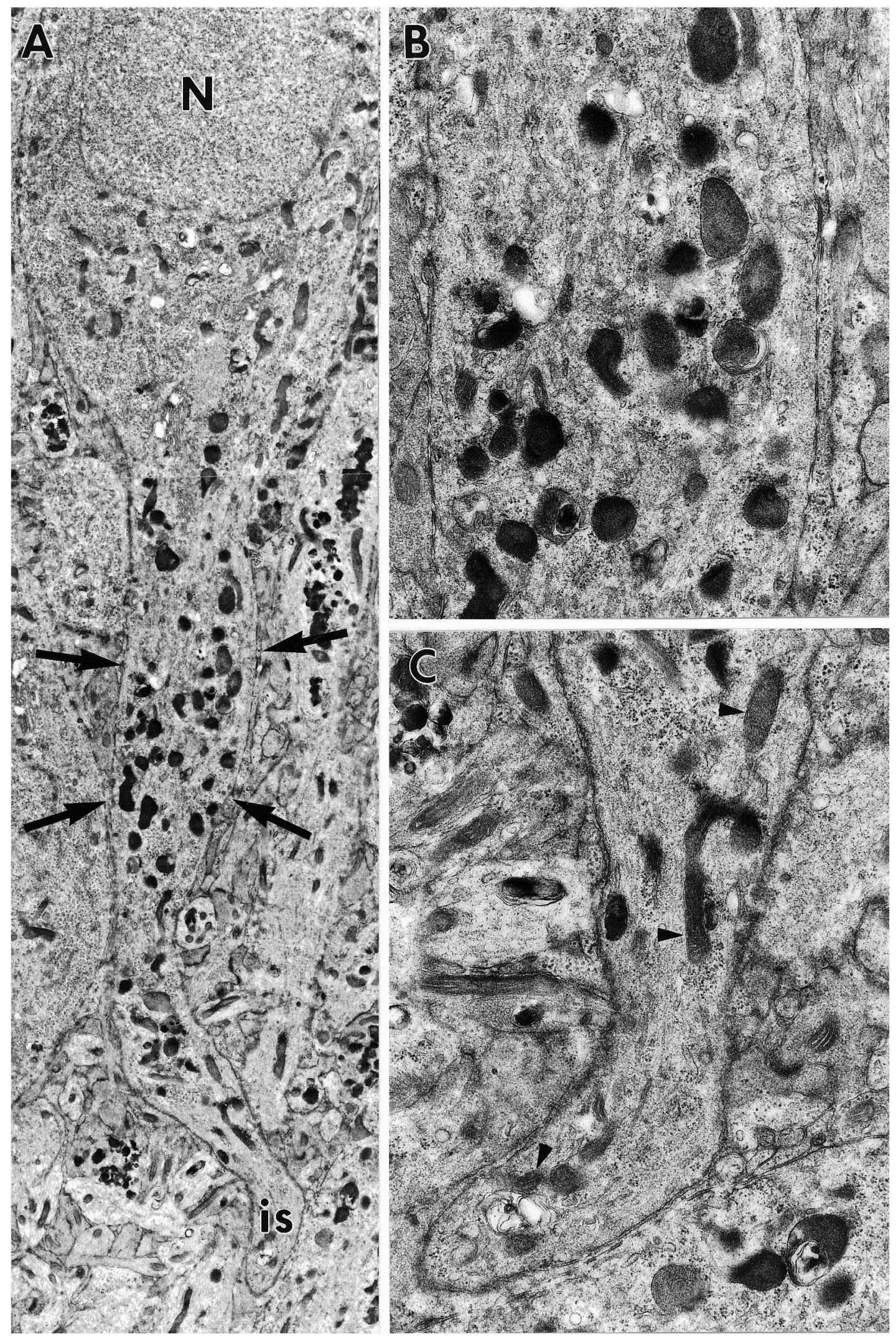

Figure 7. A, Montage of electron micrographs of a CA1 neuron $7 \mathrm{~d}$ after the conclusion of ZPAD exposure. Although the nucleus $(N)$, soma, and axon initial segment (is) appear normal, the location of the axon initial segment is distally displaced by a fusiform expansion (arrows) of the axon hillock region (meganeurite). The cytosol of the meganeurite, unlike that of the axon and soma, contains many lysosomes. Magnification, 6200×. B, Enlargement of the indicated portion of the fusiform expansion. Magnification, 18,500×. $C$, Enlargement of the region containing the axon initial segment. Note that this region contains several mitochondria (arrowheads) and a few lysosomes. Magnification, $18,500 \times$. 


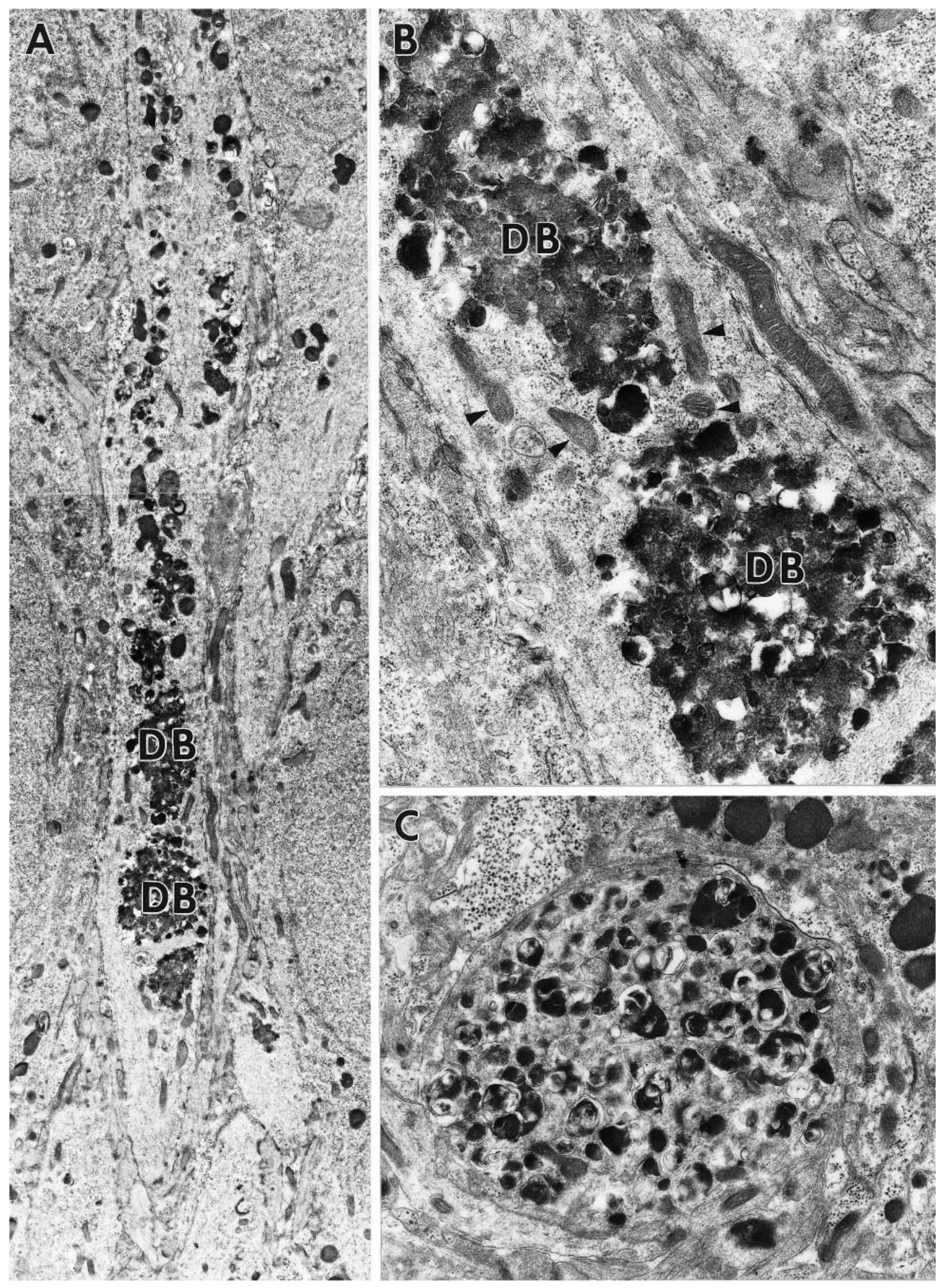

Figure 8. A, Montage of electron micrographs showing the distal portion of a meganeurite from a treated CA1 pyramidal cell. The length of the meganeurite is more than twice the diameter of the parent soma (data not shown). Note that a columnar organization of lysosomes and FDBs is found within the proximal aspects of the meganeurite (top of field). FDBs at the more distal regions of the process (bottom of field), however, are compacted into larger dense bodies $(D B)$. Magnification, $6200 \times . B$, Enlargement of the more distal segment of the meganeurite. The circular aggregates are composed of FDBs and vacuoles. Note the presence of mitochondria (arrowheads) that appear normal. Magnification, 20,000×. $C$, Micrograph of a membrane-bound cellular profile filled with FDBs observed in CA1 stratum oriens of a ZPAD-treated slice. Magnification, 13,500×. 

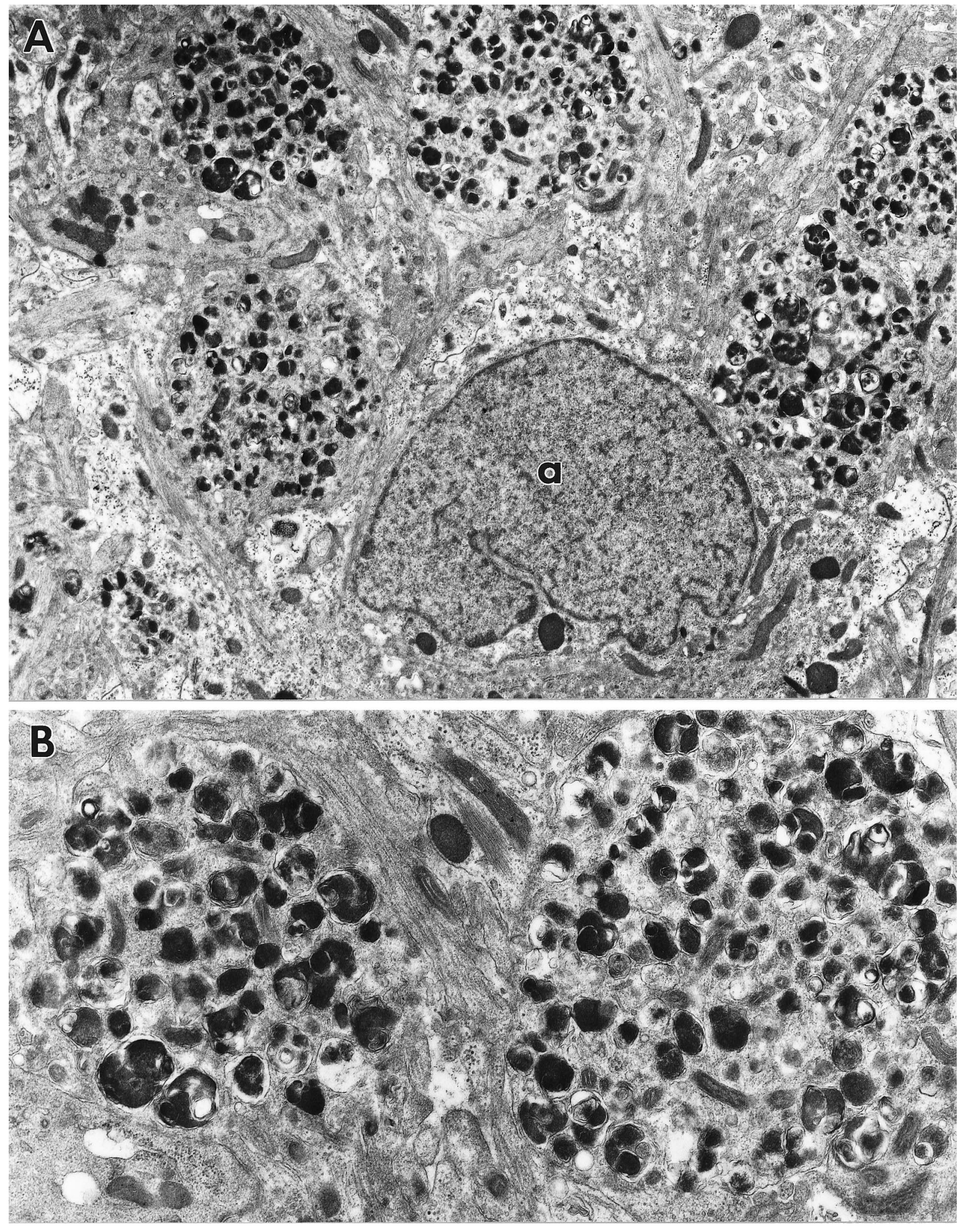

Figure 9. A, CA1 of a slice maintained in culture for 1 week after ZPAD treatment. An astrocyte $(a)$ is adjacent to several FDB-laden cellular processes. Magnification, $8500 \times . B$, Enlargement of two of the processes. Note the presence of filaments between the two profiles and the discontinuous nature of the membrane encircling the process on the left. Magnification, 18,000×. 

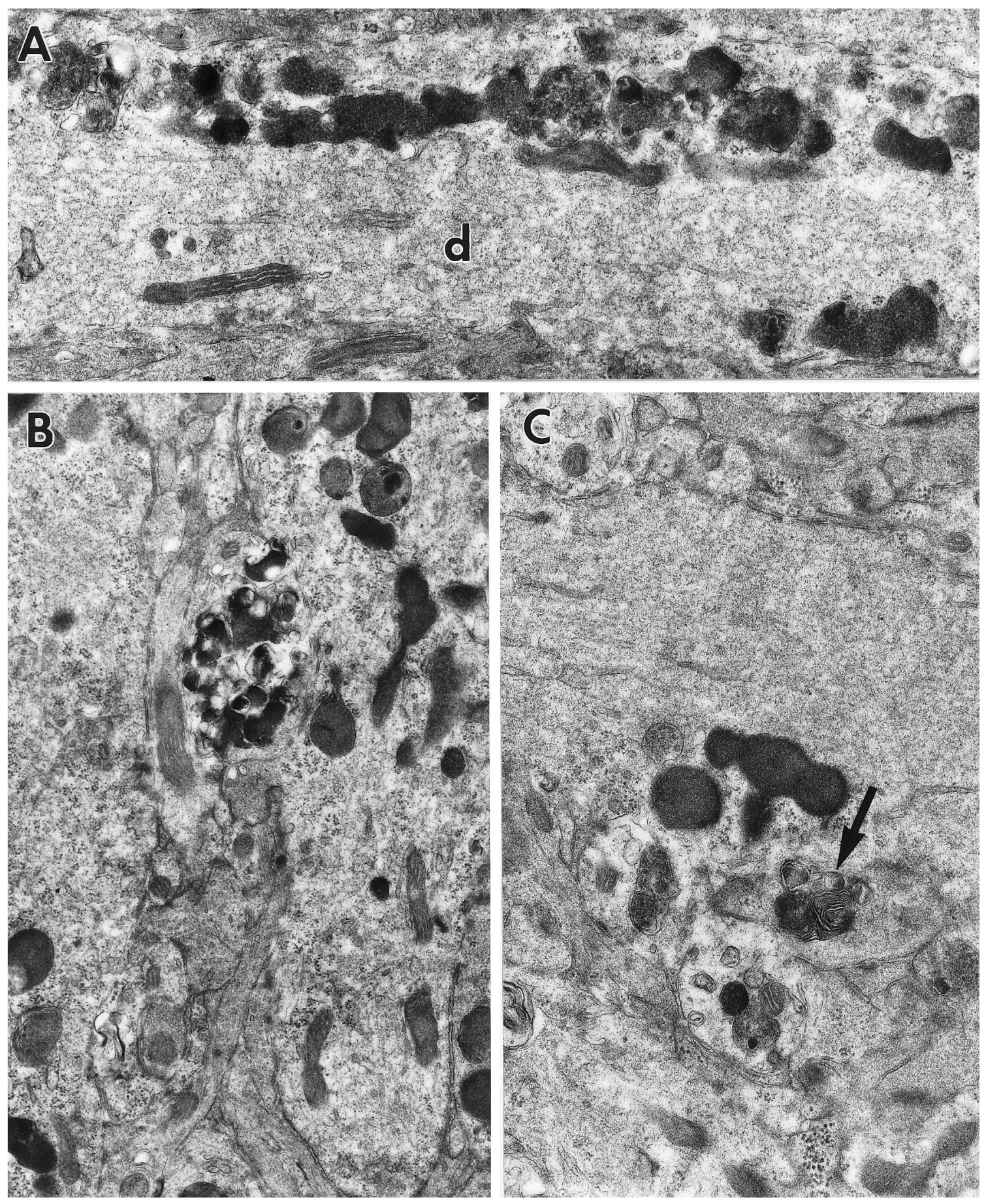

Figure 10. A, Electron micrograph of a portion of CA1 depicting an apical dendrite $(d)$ of a ZPAD-exposed slice. Clusters of FDBs line up adjacent to an irregular dendritic membrane. Magnification, 19,000×. B, A cellular process filled with FDBs apposes a concavity of a distal CA1 meganeurite. Magnification, $16,000 \times . C$, Lysosomes fill a dendritic protrusion. Note the vesicles containing residual catabolic organelles and whorled bodies (arrow) beside the excrescence. Magnification, 20,000×.

slices processed immediately after drug incubation: (1) an increase in the incidence of FDBs; (2) a marked reduction in the number of lysosomes and FDBs in the cell bodies; (3) the selective presence of lysosomes and FDBs in the axon hillock and initial segment of the axon; and (4) numerous lysosomes and FDBs within meganeurites (fusiform bodies) growing out of the perikarya. The appearance of the FDBs corresponded to that reported for secondary structures resulting from the aggregation of multiple lysosomes and their fusion with other organelles and vacuoles (Samorajski et al., 1964). In the case of the ZPAD-treated slices, the FDBs are likely the result of accumulations of proteins and lipids incompletely degraded during the $6 \mathrm{~d}$ period in which key lysosomal proteases had been inhibited. The clearing of the cell body and the immediately adjacent growth of meganeurites can reasonably be assumed to be related events; i.e., it is likely that the meganeurites are storage sites for excess catabolic organelles. This process may contribute to neuronal survival. Many 


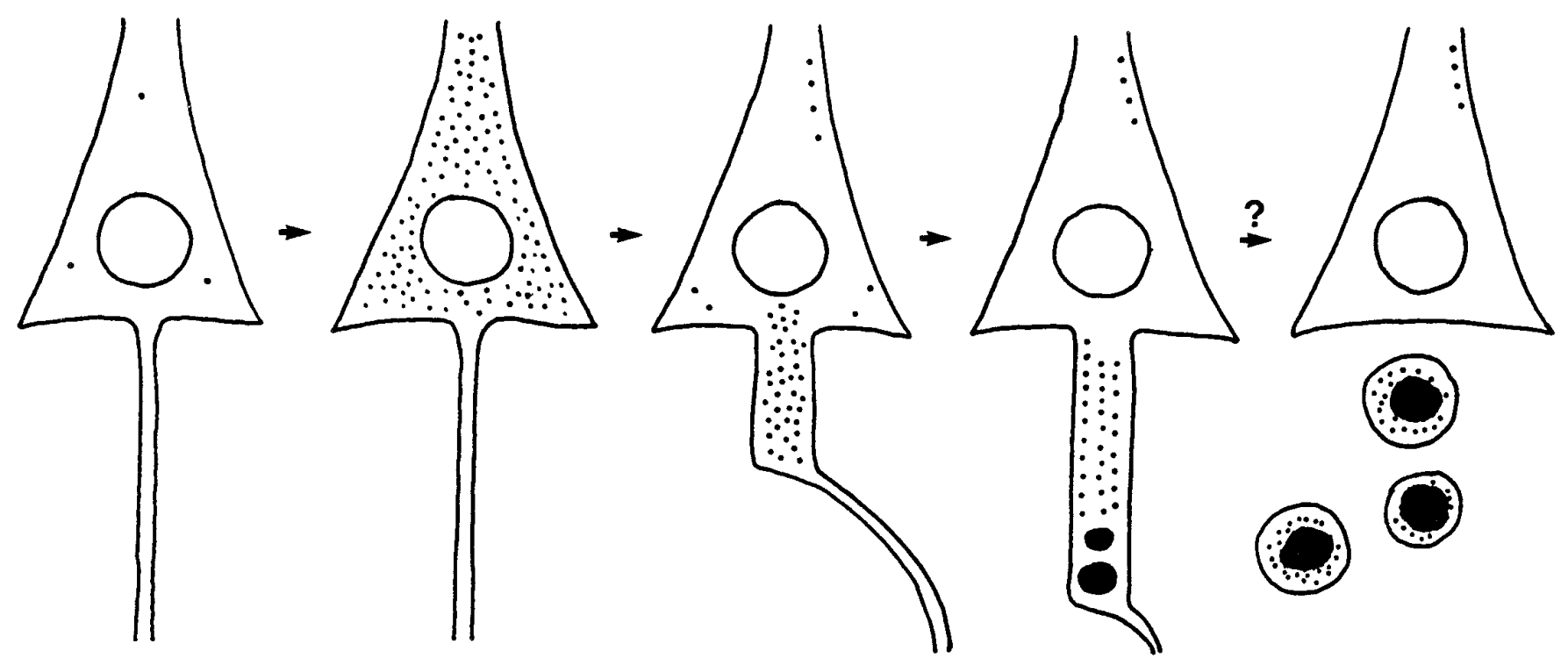

Figure 11. Schematic diagram showing a hypothetical sequence of ZPAD-induced alterations on the fine morphology of CA1 neurons. The perikaryal cytosol of a control CA1 pyramidal cell contains only three lysosomes (cell on far left). Six days of exposure to ZPAD, an inhibitor of cathepsins B and $\mathrm{L}$, result in a dramatic expansion of the lysosomal population (second cell in diagram). CA1 neurons allowed to recover for $7 \mathrm{~d}$ after ZPAD treatment restore the normal ultrastructure of the soma by sweeping the excess lysosomes and residual bodies into the axon hillock and initial segment (middle neuron). In distal portions of long "meganeurites," lysosomal bodies are fused into circular aggregates ( fourth cell). The last neuron (on the far right) depicts a hypothesized outcome of this sequence in which subsequent exocytosis of the lysosomal compactions results in pyramidal cell axotomy.

cellular functions occur within the perikaryal cytoplasm and require specific connections and spatial relationships between subcellular organelles; these could be disturbed by the presence of numerous lysosomes and large FDBs. Clearing the perikaryal cytoplasm by sequestering lysosomes into meganeurites could serve to restore the normal ultrastructure of the soma and thereby circumvent a variety of biochemical problems (Mann and Yates, 1974).

Although meganeurite formation may assist neuronal viability, these somatic appendages ultimately could have detrimental effects. Commonly located between the cell soma and initial portion of the axon, meganeurites are positioned to alter negatively the processes underlying orthograde and retrograde axonal transport; with time, this would have the effect of depriving the cell of trophic substances. It is noteworthy that the experimental paradigm produced meganeurites only in CA1 neurons, because these cells constitute the hippocampal subpopulation most vulnerable to degeneration in Alzheimer's disease (AD) (West et al., 1994). Beyond this, it is possible that meganeurites are transitional structures generated by neurons as part of an exocytotic event (Purpura and Suzuki, 1976; Cavanagh et al., 1993). Data obtained from studies on the spinal ganglion suggest that cells remove structures similar to FDBs by pinching off recently generated cytoplasmic protrusions (Spoerri and Glees, 1973). If meganeurites are eventually separated from the parent cell, then their location, commonly proximal to the axon initial segment, raises the possibility that this release event may result in axotomy.

Combining the present results with those reported previously on the effects of ZPAD leads to the following hypothesis regarding the sequence of events set in motion by suppression of cathepsins B and L. First, a rapid buildup of undigested proteins and macromolecular structures induces the expression of a subgroup of lysosomal proteases and an increase in the number of primary lysosomes. Second, leakage of cathepsin D from lysosomes causes the unusual cleavage of several proteins including tau. Third, local breakdown of the microtubular system allows lysosomes to migrate out of the cell body and gradually work their way toward distal dendrites. Fourth, lysosomes begin forming secondary structures including FDBs. Fifth, FDBs are cleared from the soma and dendrites of compromised neurons and commonly collect at the region of the axon hillock, the basal pole of CA1 neurons. Accumulations of FDBs and lysosomes trigger membrane extrusions and meganeurite formation. Sixth, meganeurites are pinched off the cells, in some cases separating the axon from the somata (Fig. 11).

Lysosomal proliferation has been observed in neurons of aged rats and humans and in vulnerable cells in AD (Terry et al., 1964; Brizzee et al., 1969; Brunk and Ericsson, 1972; Hinds and McNelly, 1979; Cataldo et al., 1996). Increased concentrations and activities of cathepsin D also occur in both conditions (Kenessey et al., 1989; Nakanishi et al., 1994; Cataldo et al., 1995), and there is also evidence that these increases are accompanied by leakage of the protease into the cytoplasm (Nakamura et al., 1989). A tau protein fragment similar in size to that generated when tau is exposed to cathepsin D is found in neurofibrillary tangles (Nieto et al., 1990; for discussion, see also Bednarski and Lynch, 1996). Translocation of lysosomes into dendrites has been reported for aged and AD brains (Terry et al., 1964; Cataldo et al., 1994), and meganeurites emerging from cell bodies are evident from early old age onward in human neurons most at risk to degeneration (Braak, 1979; Cataldo et al., 1994). Meganeurites may represent storage structures that are eventually released from neurons. If so, the somal location of these expansions indicates that neuronal deefferentation may result from this pinching-off process. Multiple occurrences of pyramidal cell axotomy would result in synaptic loss, reductions in white matter volume, deficits in axonal transport, and myelin degradation; these are four prominent features of the aged brain (Burke et al., 1990; Masliah et al., 1993; Peters et al., 1994). It is also the case that at least one aspect of the triggering event used in the cultured slice studies occurs during brain aging. As noted, the activity of cathepsin L, one of the two known targets of ZPAD, is reported to decrease with age in the 
forebrain of the rat (Nakanishi et al., 1994). The inactivation of cathepsin $\mathrm{L}$ is not attributable to a drop in the concentration of enzyme and, thus, may reflect some perturbation of intralysosomal conditions interacting with its extreme sensitivity to $\mathrm{pH}$ (Machleidt et al., 1986; Dufour et al., 1988; for discussion, see also Nakanishi et al., 1994).

In all, then, it is possible that the sequence proposed to follow on selective lysosomal dysfunction in cultured slices is a reproduction of a complex series that occurs during normal brain aging. The present work thus supports the idea that suppression of lysosomal functioning provides a means for modeling brain aging (Ivy et al., 1984; Ivy, 1992) and extends such effects to include in vitro preparations. It must be said, however, that certain prominent features of brain aging, most notably autofluorescent lipofuscin granules, were not observed in cultured slices after inhibiting cathepsins (E. Bednarski, unpublished data). This represents a significant difference from the results of in vivo studies using chloroquine or leupeptin (Ivy et al., 1984). It may be that the production of autofluorescent granules observed in vivo results not specifically from cathepsin B and L inhibition, but instead from other cellular or systemic effects of broad-range protease inhibitors. Alternatively, cultured slices may lack sequences occurring in parallel with lysosomal hyperplasia that contribute significantly to lipofuscin generation. If the latter possibility is correct, additional manipulations will be required to obtain a satisfactory approximation of the aged brain.

\section{REFERENCES}

Bahr BA, Abai B, Gall C, Vanderklish PW, Hoffman KB, Lynch G (1995a) Induction of $\beta$-amyloid-containing polypeptides in hippocampus: evidence for a concomitant loss of synaptic proteins and interactions with an excitotoxin. Exp Neurol 129:81-94.

Bahr BA, Kessler M, Rivera S, Vanderklish PW, Hall RA, Mutneja MS, Gall C, Hoffman KB (1995b) Stable maintenance of glutamate receptors and other synaptic components in long-term hippocampal slices. Hippocampus 5:425-439.

Bahr BA, Tiriveedhi S, Park GY, Lynch G (1995c) Induction of calpainmediated spectrin fragments by pathogenic treatments in long-term hippocampal slices. J Pharmacol Exp Ther 273:902-908.

Barrett AJ, Kirschke H (1981) Cathepsin B, cathepsin H, and cathepsin L. Methods Enzymol 80:535-561.

Bednarski E, Lynch G (1996) Cytosolic proteolysis of tau by cathepsin D in hippocampus following suppression of cathepsins B and L. J Neurochem 67:1846-1855.

Bednarski E, Vanderklish P, Gall C, Saido TC, Bahr BA, Lynch G (1995) Translational suppression of calpain I reduces NMDA-induced proteolysis and pathophysiology in cultured hippocampal slices. Brain Res 694:147-157.

Bohley P, Seglen PO (1992) Proteases and proteolysis in the lysosome. Experientia 48:151-157.

Braak H (1979) Spindle-shaped appendages of IIIab-pyramidals filled with lipofuscin: a striking pathological change of the senescent human isocortex. Acta Neuropathol 46:197-202.

Braak H, Goebel HH (1979) Pigmentoarchitectonic pathology of the isocortex in juvenile neuronal ceroid-lipofuscinosis: axonal enlargements in layer IIIab and cell loss in layer V. Acta Neuropathol 46:79-83.

Bradford MM (1976) A rapid and sensitive method for the quantification of microgram quantities of protein utilizing the principle of protein-dye binding. Anal Biochem 72:248-254.

Brizzee KR, Cancilla PA, Sherwood N, Timiras PS (1969) The amount and distribution of pigments in neurons and glia of the cerebral cortex. J Gerontol 24:127-135.

Brunk U, Ericsson JLE (1972) Electron microscopical studies on rat brain neurons. Localization of acid phosphatase and mode of formation of lipofuscin bodies. J Ultrastr Res 38:1-15.

Buchs P-A, Stoppini L, Muller D (1993) Structural modifications associated with synaptic development in area CA1 of rat hippocampal organotypic cultures. Dev Brain Res 71:81-91.
Burke WJ, Park DH, Chung HD, Marshall GL, Haring JH, Joh TH (1990) Evidence for decreased transport of tryptophan hydroxylase in Alzheimer's Disease. Brain Res 537:83-87.

Cataldo AM, Nixon RA (1990) Enzymatically active lysosomal proteases are associated with amyloid deposits in Alzheimer brain. Proc Natl Acad Sci USA 87:3861-3865.

Cataldo AM, Hamilton DJ, Nixon RA (1994) Lysosomal abnormalities in degenerating neurons link neuronal compromise to senile plaque development in Alzheimer disease. Brain Res 640:68-80.

Cataldo AM, Barnett JL, Berman SA, Li J, Quarless S, Bursztajn S, Lippa C, Nixon RA (1995) Gene expression and cellular content of cathepsin $\mathrm{D}$ in Alzheimer's disease brain: evidence for early up-regulation of the endosomal-lysosomal system. Neuron 14:671-680.

Cataldo AM, Hamilton DJ, Barnett JL, Paskevich PA, Nixon RA (1996) Properties of the endosomal-lysosomal system in the human central nervous system: disturbances mark most neurons in populations at risk to degenerate in Alzheimer's disease. J Neurosci 16:186-199.

Cavanagh JB, Nolan CC, Seville MP, Anderson VE, Leigh PN (1993) Routes of excretion of neuronal lysosomal dense bodies after ventricular infusion of leupeptin in the rat: a study using ubiquitin and PGP 9.5 immunocytochemistry. J Neurocytol 22:779-791.

de Duve C, Wattiaux R (1966) Functions of lysosomes. Annu Rev Physiol 28:435-492.

Dufour E, Dive V, Toma F (1988) Delineation of chicken cathepsin L secondary structure; relationship between $\mathrm{pH}$ dependence activity and helix content. Biochim Biophys Acta 955:58-64.

Dunn Jr WA (1990) Studies on the mechanisms of autophagy: maturation of the autophagic vacuole. J Cell Biol 110:1935-1945.

Goode B, Feinstein S (1994) Identification of a novel microtubule binding and assembly domain in the developmentally regulated interrepeat region of tau. J Cell Biol 124:769-782.

Gorenstein C, Ribak CE (1985) Dendritic transport. II. Somatofugal movement of neuronal lysosomes induced by colchicine: evidence for a novel transport system in dendrites. J Neurosci 5:2018-2027.

Green GD, Shaw E (1981) Peptidyl diazomethyl ketones are specific inactivators of thiol proteinases. J Biol Chem 256:1923-1928.

Hajimohammadreza I, Anderson VE, Cavanagh JB, Seville MP, Nolan CC, Anderton BH, Leigh PN (1994) beta-Amyloid precursor protein fragments and lysosomal dense bodies are found in rat brain neurons after ventricular infusion of leupeptin. Brain Res 640:25-32.

Herman B, Albertini DF (1984) A time-lapse video image intensification analysis of cytoplasmic organelle movements during endosome translocation. J Cell Biol 98:565-576.

Hinds JW, McNelly NA (1979) Aging in the rat olfactory bulb: quantitative changes in mitral cell organelles and somato-dendritic synapses. J Comp Neurol 184:811-819.

Inubushi T, Kakegawa H, Kishino Y, Katunuma N (1994) Specific assay method for the activities of cathepsin L-type cysteine proteinases. J Biochem 116:282-284.

Ivy GO (1992) Protease inhibition causes some manifestations of aging and Alzheimer's disease in rodent and primate brain. Ann NY Acad Sci 674:89-102.

Ivy GO, Shottler F, Wenzel J, Baudry M, Lynch G (1984) Inhibitors of lysosomal enzymes: accumulation of lipofuscin-like dense bodies in the brain. Science 226:985-987.

Ivy GO, Kanai S, Ohta M, Smith G, Sato Y, Kobayashi M, Kitani K (1989a) Lipofuscin-like substances accumulate rapidly in brain, retina and internal organs with cysteine protease inhibition. Adv Exp Med Biol 266:31-45.

Ivy GO, Kitani K, Ihara Y (1989b) Anomalous accumulation of tau and ubiquitin immunoreactivities in rat brain caused by protease inhibition and by normal aging: a clue to PHF pathogenesis? Brain Res 498:360-365.

Kakegawa H, Nikawa T, Tagami K, Kamioka H, Sumitani K, Kawata T, Drobnic-Kosorok M, Lenarcic B, Turk V, Katunuma N (1993) Participation of cathepsin L on bone resorption. FEBS Lett 321:247-250.

Kenessey A, Banay-Schwartz M, DeGuzman T, Lajtha A (1989) Increase in cathepsin D activity in rat brain in aging. J Neurosci Res 23:454-456.

Kirschke H, Barrett AJ (1985) Cathepsin L-a lysosomal cysteine proteinase. Prog Clin Biol Res 180:61-69.

Kominami E, Ueno T, Muno D, Katunuma N (1991) The selective role of cathepsins B and D in the lysosomal degradation of endogenous and exogenous proteins. FEBS Lett 287:189-192.

Laemmli UK (1970) Cleavage of structural proteins during the assembly of the bacteriophage T4. Nature 227:680-685. 
Lee KS, Frank S, Vanderklish P, Arai A, Lynch G (1991) Inhibition of proteolysis protects hippocampal neurons from ischemia. Proc Natl Acad Sci USA 88:7233-7237.

Machleidt W, Ritonja A, Popovic T, Kotnik M, Brzin J, Turk V, Machleidt I, Muller-Esterl W (1986) Human cathepsins B, H, and L: characterization by amino acid sequences and some kinetics of inhibition by the kininogens. In: Cysteine proteinases and their inhibitors (Turk V, ed), pp 3-18. Berlin: Walter de Gruyter.

Mann DMA, Yates PO (1974) Lipoprotein pigments-their relationship to ageing in the human nervous system. Brain 97:481-488.

Masliah E, Mallory M, Hansen L, DeTeresa R, Terry RD (1993) Quantitative synaptic alterations in the human neocortex during normal aging. Neurology 43:192-197.

Muller D, Buchs P-A, Stoppini L (1993) Time course of synaptic development in hippocampal organotypic cultures. Dev Brain Res 71:93-100.

Nakamura Y, Takeda M, Suzuki H, Morita H, Tada K, Hariguchi S, Nishimura R (1989) Lysosome instability in aged rat brain. Neurosci Lett 97:215-220.

Nakanishi H, Tominaga K, Amano T, Hirotsu I, Inoue T, Yamamoto K (1994) Age-related changes in activities and localizations of cathepsin D, E, B, and L in the rat brain tissues. Exp Neurol 126:119-128.

Neff NT, DeMartino GN, Goldberg AL (1979) The effect of protease inhibitors and decreased temperature on the degradation of different classes of proteins in cultured hepatocytes. J Cell Physiol 101:439-457.

Nieto A, Montejo de Garcini E, Correas I, Avila J (1990) Characterization of tau protein present in microtubules and paired helical filaments of Alzheimer's disease patient's brains. Neuroscience 37:163-170.

Nunomura A, Miyagishi T (1993) Ultrastructural observations on a neuronal lipofuscin (age pigment) and dense bodies induced by a proteinase inhibitor, leupeptin, in rat hippocampus. Acta Neuropathol 86:319-328.

Ohkuma S (1987) The lysosomal proton pump and its effect on protein breakdown. In: Lysosomes: their role in protein breakdown (Glaumann H, Ballard FJ, eds), pp 115-148. London: Academic.

Peters A, Palay SL, Webster H (1991) The fine structure of the nervous system: neurons and their supporting cells. New York: Oxford UP.

Peters A, Leahu D, Moss MB, McNally KJ (1994) The effects of aging on area 46 of the frontal cortex of the rhesus monkey. Cereb Cortex 4:621-635.

Pliura DH, Bonaventura BJ, Smith RA, Coles PJ, Krantz A (1992) Comparative behaviour of calpain and cathepsin B toward peptidyl acyloxymethyl ketones, sulphonium methyl ketones and other potential inhibitors of cysteine proteinases. Biochem J 288:759-762.

Purpura DP, Suzuki K (1976) Distortion of neuronal geometry and formation of aberrant synapses in neuronal storage disease. Brain Res 116:1-21.

Purpura DP, Pappas GD, Baker HJ (1978) Fine structure of meganeurites and secondary growth processes in feline GM1-gangliosidosis. Brain Res 143:1-12.

Samorajski T, Keefe JR, Ordy JM (1964) Intracellular localization of lipofuscin age pigments in the nervous system. J Gerontol 19:262-276.

Shibata M, Kanai S, Ivy GO, Ohta M, Asakura M, Aoba A, Hasegawa K, Kitani K (1992) Intraventricular infusion of leupeptin decreases Bmax of the D2 receptor in the striatum of young rats. Life Sci 50:1451-1457.

Spoerri PE, Glees P (1973) Neuronal aging in culture: an electronmicroscopic study. Exp Gerontol 8:259-263.

Stoppini L, Buchs P-A, Muller D (1991) A simple method for organotypic cultures of nervous tissues. J Neurosci Methods 37:173-182.

Takauchi S, Miyoshi K (1995) Cytoskeletal changes in rat cortical neurons induced by long-term intraventricular infusion of leupeptin. Acta Neuropathol 89:8-16.

Terry RD, Gonatas NK, Weiss M (1964) Ultrastructural studies in Alzheimer's presenile dementia. Am J Pathol 44:269-297.

Toyo-Oka T, Shimizu T, Masaki T (1978) Inhibition of proteolytic activity of calcium activated neutral protease by leupeptin and antipain. Biochem Biophys Res Commun 82:484-491.

Vanderklish P, Bednarski E, Lynch G (1996) Translational suppression of calpain blocks long-term potentiation. Learning Memory 3:209-217.

Weingarten M, Lockwood A, Hwo S, Kirschner M (1975) A protein factor essential for microtubule assembly. Proc Natl Acad Sci USA 72:1858-1862.

West MJ, Coleman PD, Flood DG, Troncoso JC (1994) Differences in the pattern of hippocampal neuronal loss in normal ageing and Alzheimer's disease. Lancet 344:769-772. 